\title{
Tigloside: a New Tigloylated Tetrasaccharide from Amycolatopsis sp.†
}

\author{
Jens Breinholt, ${ }^{a}$ Andreas Kulik, ${ }^{\text {b }}$ Hanne Gürtler ${ }^{a}$ and Hans-Peter Fiedler ${ }^{\text {b,* }}$ \\ a Novo Nordisk A/S, Novo Allé, DK-2880 Bagsværd, Denmark and ' Universität Tübingen, Biologisches Institut, \\ Auf der Morgenstelle 28, D-72076 Tübingen, Germany
}

\begin{abstract}
Breinholt, J., Kulik, A., Gürtler, H. and Fiedler, H.-P., 1998. Tigloside: a New Tigloylated Tetrasaccharide from Amycolatopsis sp. - Acta Chem. Scand. 52: 1239-1242. (C) Acta Chemica Scandinavica 1998.

A novel secondary metabolite, tigloside $\left(\mathrm{C}_{54} \mathrm{H}_{78} \mathrm{O}_{27}\right)$, was detected in the mycelium of the actinomycete strain Amycolatopsis sp. NN0 21702 by HPLC diode array screening. The compound was isolated by chromatographic methods, and its structure established as $2,2^{\prime}$-di- $O$ - $\{3,4-\mathrm{di}-O-[(E)-2$-methyl-2-butenoyl $]-\beta$ D-glucopyranosyl $\}$-6,6'-di- $O$ - $[(E)$-2-methyl-2-butenoyl $]-[\alpha$-D-glucopyranosyl $\alpha$-Dglucopyranoside] by NMR spectroscopic methods and chemical degradation experiments.
\end{abstract}

A prerequisite for an efficient screening program for new natural substances is an analytical tool that allows rapid identification of known and detection of new compounds at a very early stage of the investigation. Our approach has been to use reversed-phase HPLC coupled with diode array detection (HPLC-DAD) to screen micro-organisms for production of secondary metabolites. ${ }^{2}$ Culture filtrates and extracts from culture filtrates and mycelia are analysed by HPLC-DAD, and the UV-VIS spectra of the resulting chromatographic peaks are compared with those of reference compounds stored in our HPLC-UV-VIS database. Known metabolites are identified and new characterised according to their retention times and UV-VIS properties.

Actinomycetes represent an astonishingly diverse and apparently inexhaustible source of secondary metabolites. Even though the majority of reported secondary metabolite discoveries is still related to the genus Streptomyces, ${ }^{3,4}$ the non-Streptomyces actinomycetes, also referred to as 'rare' actinomycetes, may well prove to be an equally fruitful source of new, interesting natural substances, provided that proper conditions supporting growth as well as expression of secondary metabolites can be established. The cultivation of Amycolatopsis sp. NN0 21702 using various media compositions led to the production of a novel secondary metabolite detected by HPLC-DAD analysis of the culture extract, when the organism was grown under specific cultivation conditions. Comparison of retention time and UV-VIS characteristics recorded for the Amycolatopsis-metabolite with

$\dagger$ Article No. 11 in the series 'Biosynthetic Capacities of Actinomycetes'. Part 10: See Ref. 1.

* To whom correspondence should be addressed. those stored in our HPLC-UV-VIS database implied that the compound was new. Structural characterisation by means of spectroscopic and chemical methods confirmed the novelty of the compound, a symmetrical tetrasaccharide esterified in six positions with tiglic acid [(E)-2-methyl-2-butenoic acid]. Accordingly, the compound was named tigloside. In this paper we wish to describe the screening procedure, fermentation, isolation and structure elucidation of tigloside.

\section{Screening and fermentation}

A crude extract of the culture broth of Amycolatopsis sp. NN0 21702 was screened by our HPLC-DAD method. ${ }^{2}$ The elution profile was characterised by one single dominant peak with a retention time of $10.4 \mathrm{~min}$ and exhibiting a UV absorption maximum at $222 \mathrm{~nm}$ (Fig. 1). Lack of spectral matches among the approximately 500 reference compounds stored in our HPLC-UV-VIS database prompted us to undertake the isolation and structure elucidation of the unknown metabolite.

Batch fermentations of Amycolatopsis sp. NN0 21702 were carried out in a 10-litre stirred tank fermenter using a complex medium. Production of tigloside started at about 5 days and reached a maximum of $125 \mathrm{mg}^{-1}$ after an incubation period of 13 days. The maximal production of tigloside correlated with the maximal amount of biomass formation. Tigloside was isolated from the mycelium by extraction with EtOH. Concentration of the EtOH layer and addition of water led efficiently to quantitative precipitation of tigloside as white flocks with a purity estimated to be more than $60 \%$. Attempts to purify tigloside further by silica gel or 


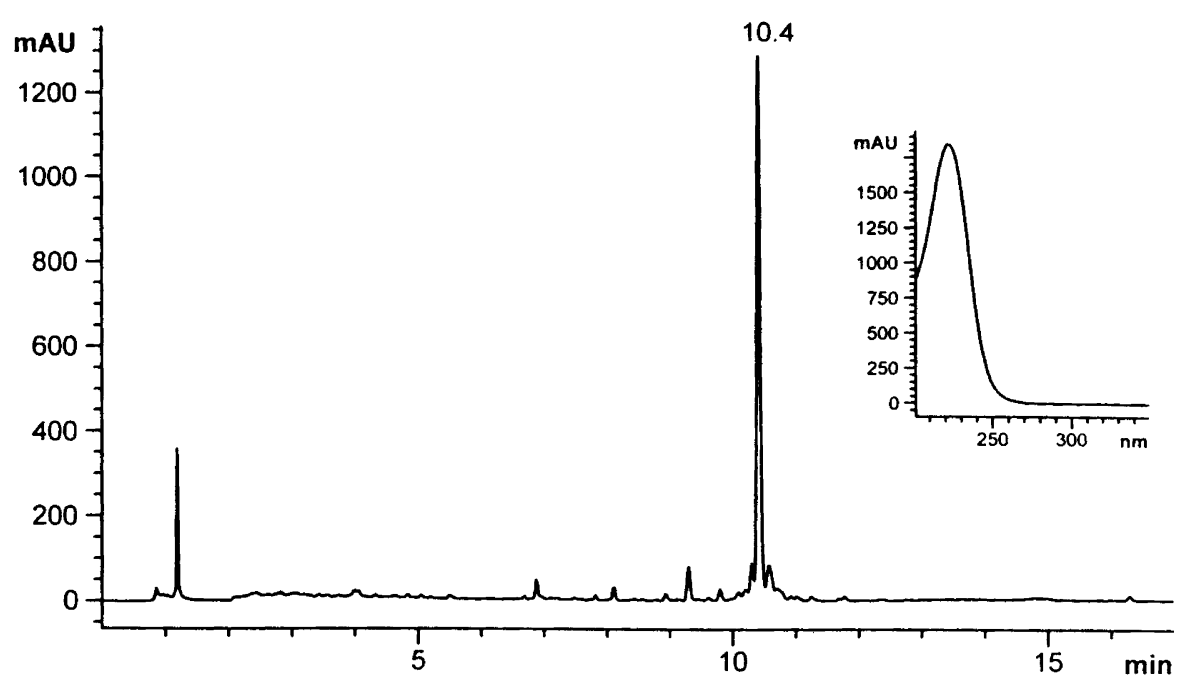

Fig. 1. HPLC analysis of the mycelium extract from Amycolatopsis sp. NNO 21702 monitored at $210 \mathrm{~nm}$ and UV spectrum of tigloside $(10.4 \mathrm{~min})$.

Sephadex LH-20 chromatography resulted in poor separations and yields, whereas preparative reversed-phase HPLC using LiChrospher RP-Select B material proved highly efficient. Thus, pure tigloside was obtained, virtually in quantitative yields, by $\mathrm{H}_{2} \mathrm{O}-\mathrm{MeOH}$ gradient elution, and appeared after lyophilisation as a colourless, amorphous powder.

\section{Structure elucidation}

The structure of tigloside was established as 2,2'di- $O$ - $\{3,4$-di- $O$ - $[(E)-2$-methyl-2-butenoyl $]-\beta$-D -glucopyranosyl $\}-6,6^{\prime}-\mathrm{di}-O-[(E)-2$-methyl-2-butenoyl $]-[\alpha-\mathrm{D}$ glucopyranosyl $\alpha$-D-glucopyranoside] (1) by NMR spectroscopic methods, including DEPT, COSY, TOCSY, HSQC, HSQC-TOCSY and HMBC, MS analysis, and chemical degradation experiments.

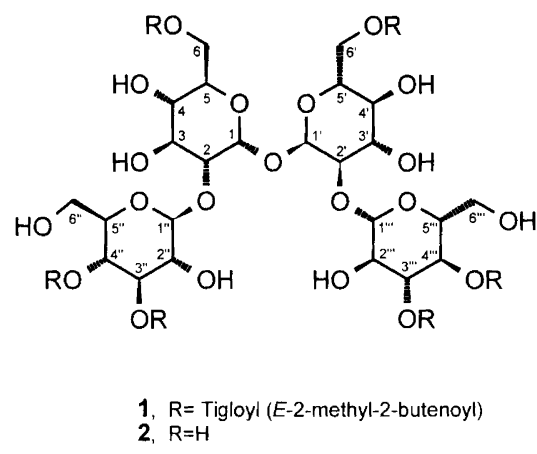

Correlations observed in COSY, TOCSY and HSQC spectra, in combination with analysis of vicinal ${ }^{1} \mathrm{H},{ }^{1} \mathrm{H}$ coupling constants, revealed the presence of two separate spin systems attributable to one $\alpha$ - and one $\beta$-glucopyranose unit. In addition to the carbohydratederived signals the NMR spectra exhibited resonances corresponding to three non-equivalent 2-methyl-2-butenoyl moieties, which, based on their NMR character- istics, were demonstrated to have the $E$-configuration (tigloyl).

Electrospray mass spectrometry (ES-MS) established the molecular weight of tigloside as 1158 , suggesting an acylated, and, to conform with NMR data, symmetrical tetrasaccharide. Significant down-field shifts for C-2/2' ( $\delta$ 81.6) implied glucosylation in the $2 / 2^{\prime}$-position, which was confirmed by long-range ${ }^{1} \mathrm{H},{ }^{13} \mathrm{C}$-correlations observed in the HMBC spectrum across the glucosidiclinkage from $\mathrm{H}-2 / 2^{\prime}$ to $\mathrm{C}-1^{\prime \prime} / 1^{\prime \prime \prime}$ and in the reverse direction from $\mathrm{H}-1^{\prime \prime} / 1^{\prime \prime \prime}$ to $\mathrm{C}-2 / 2^{\prime}$. The sites of acylation were unambiguously determined by HMBC-correlations from $\mathrm{H}_{2}-6 / 6^{\prime}, \mathrm{H}-3^{\prime \prime} / 3^{\prime \prime \prime}$ and $\mathrm{H}-4^{\prime \prime} / 4^{\prime \prime \prime}$ to the individual tiglic ester carbonyl carbon atoms. An HMBC-correlation observed between $\mathrm{H}-1 / 1^{\prime}$ and $\mathrm{C}-1^{\prime} / 1$, reflecting the presence of a long-range coupling from the anomeric proton in one half of the molecule across the glucosidic linkage to the anomeric carbon in the other half, served to substantiate a composition of two identically substituted glucobiose units connected via an $\alpha, \alpha-(1 \rightarrow 1)$-glucosidic linkage.

Deacylation of tigloside afforded a tetrasaccharide, the structure of which was established as $2,2^{\prime}$-di- $O-\beta-\mathrm{D}-$ glucopyranosyl- $\alpha$-D-glucopyranosyl $\alpha$-D-glucopyranoside (2) by the same array of 1- and 2D-NMR techniques utilised in the structural characterisation of tigloside. Hydrolysis of $\mathbf{2}$ under acidic conditions yielded the constituent monosaccharide, D-glucose. Thus, the structure of tigloside was firmly established as $2,2^{\prime}$-di- $O-\{3,4-$ di- $O$ - $[(E)-2$-methyl-2-butenoyl $]-\beta$-D-glucopyranosyl $\}$ 6,6'-di-O-[(E)-2-methyl-2-butenoyl ]-[ $\alpha$-D-glucopyranosyl $\alpha$-D-glucopyranoside] (1).

\section{Discussion}

Tigloside constitutes a structurally quite unusual addition to the large group of actinomycete-derived natural products. The characteristic $\alpha$-D-glucopyranosyl $\alpha$-D-gluco- 
pyranoside moiety, a structural element shared with $\alpha, \alpha-$ trehalose ( $\alpha$-D-glucopyranosyl $\alpha$-D-glucopyranoside) found in insects and fungi, has to our knowledge not previously been encountered in metabolic products of actinomycetes. Furthermore, tigloyl esters, which are commonly occurring constituents of higher plants, appear to be unprecedented as a secondary metabolite of an actinomycete strain.

Two further Amycolatopsis strains were investigated for production of $\mathbf{1}$. However, tigloside could not be detected in cultures of either A. mediterranei FH1972, the producer of the glycopeptide antibiotic balhimycin, ${ }^{5}$ or A. orientalis MG417-CF17, the producer of ethylenediaminedisuccinic acid. ${ }^{6}$

Tigloside exhibited no antimicrobial activity at a concentration of $1 \mathrm{mg} \mathrm{ml}^{-1}$ by the agar plate diffusion assay against various Gram-positive and Gram-negative bacteria, yeasts and filamentous fungi, and no herbicidal activity against Lemna minor could be observed. Therefore, further testing would be worthwhile so that the biological potential of this novel compound can be explored.

\section{Experimental}

General. The analytical HPLC system consisted of an HP 1090M liquid chromatograph equipped with a built-in diode array detector, HP 3D-DOS ChemStation and software revision 3.01 (Hewlett-Packard). Multiple wavelength monitoring was performed at $210,230,260$, $280,310,360$ and $435 \mathrm{~nm}$ without reference wavelength; the spectrum range was $200-600 \mathrm{~nm}$ in steps of $2 \mathrm{~nm}$ and sampling intervals of $640 \mathrm{~ms}$. Preparative HPLC was performed on a system consisting of two highpressure pumps (Sepapress HPP-200/100; Kronwald), gradient unit (Sepacon GCU-311), Valco preparative injection valve (6UW; VICI) with 5-ml sample loop, and a dual wavelength UV-detector (Model 116, Gilson) equipped with a preparative cell (path-length $0.2 \mathrm{~mm}$ ).

${ }^{1} \mathrm{H}$ and ${ }^{13} \mathrm{C}$ NMR data were acquired at $300 \mathrm{~K}$ on Bruker AC300P or DRX400 instruments. Chemical shifts $\left(\delta\right.$-values) are in ppm. Spectra acquired in $\left({ }^{2} \mathrm{H}_{4}\right)$ methanol are referenced to the solvent signals at $\delta 3.30\left({ }^{1} \mathrm{H}\right)$ and $\delta 49.0\left({ }^{13} \mathrm{C}\right)$, and in the case of $\mathrm{D}_{2} \mathrm{O}$ to $\delta 4.70\left({ }^{1} \mathrm{H}\right)$ and $\delta 67.4\left({ }^{13} \mathrm{C}, 1,4\right.$-dioxane $)$. Electrospray mass spectrometry (ES-MS) was performed on a Sciex API III instrument.

Screening method. Strain NN0 21702 was identified as a producer of tigloside by the HPLC-DAD screening technique. Ten $\mathrm{ml}$ of culture broth were extracted with $5 \mathrm{ml}$ of EtOAc. The organic layer was evaporated to dryness and residue resuspended in $0.5 \mathrm{ml}$ of $\mathrm{MeOH}$. $10 \mu \mathrm{l}$ were injected onto a HPLC column ( $125 \mathrm{~mm} \times 4.6 \mathrm{~mm}$ i.d.) fitted with a guard column $(20 \mathrm{~mm} \times 4.6 \mathrm{~mm}$ i.d.), which was packed with $5 \mu \mathrm{m}$ Nucleosil-100 C-18 (Grom). The constituents were separated by gradient elution using $0.1 \%$ phosphoric acid (solvent A) and acetonitrile (solvent B). The linear gradient was from $0 \%$ to $100 \%$ solvent $\mathrm{B}$ over $15 \mathrm{~min}$ with a 1 -min hold at $100 \% \mathrm{~B}$ and a 5 -min post-time under initial conditions, at a flow rate of $2 \mathrm{ml} \mathrm{min}^{-1}$.

Fermentation, isolation and purification of tigloside (1). Amycolatopsis sp. NN0 21702 was grown at $27^{\circ} \mathrm{C}$ for 13 days (aeration rate $0.5 \mathrm{v} / \mathrm{v} / \mathrm{m}$, agitation $300 \mathrm{rpm}$ ) in a 10-litre bioreactor (NB 10; New Brunswick) using a production medium composed of (per litre): $20 \mathrm{~g}$ glucose, $20 \mathrm{~g}$ galactose, $10 \mathrm{~g}$ Bacto-soytone, $2 \mathrm{~g}\left(\mathrm{NH}_{4}\right)_{2} \mathrm{SO}_{4}$, and $2 \mathrm{~g} \mathrm{CaCO}_{3}$; the $\mathrm{pH}$ was adjusted to 7.4. The medium was inoculated with 5 vol\% of shaking cultures grown for 3 days in the same medium.

Hyflo Super-cel (3\%) was added to the fermentation broth which was separated by multiple sheet filtration into culture filtrate and mycelium cake. Tigloside (1) was located in the mycelium which was extracted three times with EtOH. The combined extracts were concentrated in vacuo. After addition of $\mathrm{H}_{2} \mathrm{O}$, tigloside precipitated as white flocks which were filtered off and washed with water $(2.1 \mathrm{~g})$. Aliquots of $150 \mathrm{mg}$ were dissolved in $\mathrm{MeOH}(2 \mathrm{ml})$, diluted with $\mathrm{H}_{2} \mathrm{O}(0.5 \mathrm{ml})$, and purified by preparative reversed-phase HPLC using a stainless steel column $(250 \mathrm{~mm} \times 16 \mathrm{~mm}$ i.d. $)$ filled with $10-\mu \mathrm{m}$ LiChrospher RP-Select B. The column was eluted with a $\mathrm{H}_{2} \mathrm{O}-\mathrm{MeOH}$ gradient, starting from $60 \% \mathrm{MeOH}$ to $90 \% \mathrm{MeOH}$ over $15 \mathrm{~min}$ at a flow rate of $20 \mathrm{ml} \mathrm{min}^{-1}$. The UV absorbance of the eluate was monitored simultaneously at 230 and $250 \mathrm{~nm}$.

Physical, chemical and spectroscopic properties. Homogeneous tigloside (1), after lyophilisation, was obtained as a colourless, amorphous solid: ${ }^{1} \mathrm{H}$ and ${ }^{13} \mathrm{C}$ NMR data are presented in Table 1. Anal. $\mathrm{C}_{54} \mathrm{H}_{78} \mathrm{O}_{27}, \mathrm{H}_{2} \mathrm{O}: \mathrm{C}, \mathrm{H}$. ES-MS: $m / z 1557\left([M-\mathrm{H}]^{-}\right)$and $1181\left([M+\mathrm{Na}]^{+}\right) ;[a]_{\mathrm{D}}^{24}=+52^{\circ}(c=0.7, \mathrm{MeOH}) ; \mathrm{IR}$ (KBr): $3441,2927,1712,1648,1271,1155$ and $1077 \mathrm{~cm}^{-1}$; UV data are presented in Fig. 1. Tigloside readily dissolves in $\mathrm{MeOH}$, EtOH, PrOH, BuOH, DMSO, THF and dioxane, is sparingly soluble in acetone, methyl ethyl ketone, EtOAc and dichloromethane, but insoluble in water and $n$-hexane. Tigloside is detectable by TLC (Merck silica gel 60) with an $R_{\mathrm{f}}$-value of 0.4 in the solvent system $\mathrm{CH}_{2} \mathrm{Cl}_{2}-\mathrm{MeOH}-\mathrm{AcOH}(90: 10: 1)$ using different staining reagents. The colour reaction with anisaldehyde $-\mathrm{H}_{2} \mathrm{SO}_{4}$ resulted in a green spot, whereas naphthoresorcine- $\mathrm{H}_{2} \mathrm{SO}_{4}$ led to a violet spot.

2,2'-Di-O- $\beta$-D-glucopyranosyl- $\alpha$-D-glucopyranosyl $\quad \alpha$-Dglucopyranoside (2). Tigloside (1) (4 mg) was dissolved $0.1 \mathrm{M} \mathrm{NaOMe}-\mathrm{MeOH}(2.0 \mathrm{ml})$ and stirred at room temperature for $1 \mathrm{~h}$. After neutralisation by addition of ion exchange resin (Dowex $\mathrm{AG} 50 \mathrm{~W}, \mathrm{H}^{+}$) the solvent was evaporated off to yield $2(1 \mathrm{mg})$ as an amorphous glass. ${ }^{1} \mathrm{H}$ NMR $\left(\mathrm{D}_{2} \mathrm{O}\right): \delta 5.25\left(\mathrm{~d}, J_{1,2}=3.5 \mathrm{~Hz}\right), 3.63$ $\left(\mathrm{dd}, J_{2,3}=9.6 \mathrm{~Hz}\right), 3.90\left(\mathrm{t}, J_{3,4}=9.4 \mathrm{~Hz}\right), 3.48\left(\mathrm{t}, J_{4,5}=\right.$ 
Table 1. ${ }^{1} \mathrm{H}$ and ${ }^{13} \mathrm{C}$ NMR data for tigloside (1) in $\left({ }^{2} \mathrm{H}_{4}\right)$ methanol.

\begin{tabular}{|c|c|c|}
\hline & ${ }^{13} \mathrm{C}$ & ${ }^{1} \mathrm{H}$ \\
\hline $\begin{array}{l}1 / 1^{\prime} \\
2 / 2^{\prime} \\
3 / 3^{\prime} \\
4 / 4^{\prime} \\
5 / 5^{\prime} \\
6 / 6^{\prime}\end{array}$ & $\begin{array}{l}95.7 \\
81.6 \\
73.9 \\
71.2 \\
71.2 \\
63.4\end{array}$ & $\begin{array}{l}5.29\left(\mathrm{~d}, J_{1,2}=3.4 \mathrm{~Hz}\right) \\
3.66\left(\mathrm{dd}, J_{2,3}=11.3 \mathrm{~Hz}\right) \\
3.92\left(\mathrm{t}, J_{3,4}=11.3 \mathrm{~Hz}\right) \\
3.55\left(\mathrm{dd}, J_{4,5}=9.9 \mathrm{~Hz}\right) \\
4.20\left(\mathrm{dt}, J_{5,6 \mathrm{a}}=2.4 \mathrm{~Hz}, J_{5,6 \mathrm{~b}}=2.6 \mathrm{~Hz}\right. \\
4.35 / 4.53\left(\mathrm{dd}, J_{6 \mathrm{a}, 6 \mathrm{~b}}=12.0 \mathrm{~Hz}\right)\end{array}$ \\
\hline $\begin{array}{l}1 " / 1^{\prime \prime \prime} \\
2^{\prime \prime} / 2^{\prime \prime \prime} \\
3^{\prime \prime} / 3^{\prime \prime \prime} \\
4^{\prime \prime} / 4^{\prime \prime \prime} \\
5^{\prime \prime} / 5^{\prime \prime \prime} \\
6^{\prime \prime} / 6^{\prime \prime \prime}\end{array}$ & $\begin{array}{r}105.8 \\
73.8 \\
76.3 \\
70.9 \\
76.2 \\
62.4\end{array}$ & $\begin{array}{l}4.70\left(\mathrm{~d}, J_{1^{\prime \prime}, 2^{\prime \prime}}=7.8 \mathrm{~Hz}\right) \\
3.50\left(\mathrm{dd}, J_{2^{\prime \prime}, 3^{\prime \prime}}=9.5 \mathrm{~Hz}\right) \\
5.24\left(\mathrm{t}, J_{3^{\prime \prime}, 4^{\prime \prime}}=9.5 \mathrm{~Hz}\right) \\
4.92\left(\mathrm{t}, J_{4^{\prime \prime}, 5^{\prime \prime}}=9.6 \mathrm{~Hz}\right) \\
3.65 \text { (ddd, } J_{5^{\prime \prime}, 6 \mathrm{a}}=2.4 \mathrm{~Hz}, \\
\left.J_{5^{\prime \prime}, 6 \mathrm{~b}}=3.1 \mathrm{~Hz}\right) \\
3.59 \text { (AB-mult.) }\end{array}$ \\
\hline 6/6'-Tigloyl & $\begin{array}{r}169.5 \\
129.7 \\
138.9 \\
14.5 \\
12.3\end{array}$ & $\begin{array}{l}6.92(\mathrm{dq}), J=7.1 \text { and } 1.5 \mathrm{~Hz} \\
1.83(\mathrm{dq}), J=7.1 \text { and } 1.1 \mathrm{~Hz} \\
1.87(\mathrm{~m})\end{array}$ \\
\hline $4^{\prime \prime \prime} / 4^{\prime \prime \prime}-$ Tigloyl & $\begin{array}{c}168.2 \\
129.0 \\
139.3 \\
14.5^{a} \\
12.1^{b}\end{array}$ & $\begin{array}{l}6.81^{c} \\
1.77^{c} \\
1.74^{c}\end{array}$ \\
\hline $3^{\prime \prime} / 3^{\prime \prime \prime}-$ Tigloyl & $\begin{array}{c}168.8 \\
129.3 \\
140.0 \\
14.4^{a} \\
12.0^{b}\end{array}$ & $\begin{array}{l}6.81^{c} \\
1.77^{c} \\
1.77^{c}\end{array}$ \\
\hline
\end{tabular}

$a^{a, b}$ Signals with the same superscript are interchangeable. ${ }^{c}$ Multiplicity as for the $6 / 6$ '-tigloyl group.
$9.6 \mathrm{~Hz}$ ), 3.91 (m), 3.76 (AB-mult.) (H-1/1' to $\left.\mathrm{H}-6 / 6^{\prime}\right)$, $4.53\left(\mathrm{~d}, J_{1^{\prime \prime}, 2^{\prime \prime}}=7.8 \mathrm{~Hz}\right), 3.19\left(\mathrm{dd}, J_{2^{\prime \prime}, 3^{\prime \prime}}=9.3 \mathrm{~Hz}\right), 3.42$ $\left(\mathrm{t}, J_{3^{\prime \prime}, 4^{\prime \prime}}=9.1 \mathrm{~Hz}\right), 3.27\left(\mathrm{dd}, J_{4^{\prime \prime} 5^{\prime \prime}}=7.4 \mathrm{~Hz}\right), 3.36(\mathrm{ddd}$, $J_{5^{\prime \prime}, 6 \mathrm{a}^{\prime \prime}}=2.1 \mathrm{~Hz}$ and $\left.J_{5^{\prime \prime}, 6 \mathrm{~b}^{\prime \prime}}=6.3 \mathrm{~Hz}\right)$ and $3.62 / 3.83(\mathrm{dd}$, $\left.J_{6 \mathrm{a} "}{ }^{\prime \prime} \mathrm{b}^{\prime \prime}=12.4 \mathrm{~Hz}\right)\left(\mathrm{H}-1^{\prime \prime} / 1^{\prime \prime \prime}\right.$ to $\left.\mathrm{H}-6^{\prime \prime} / 6^{\prime \prime \prime}\right) .{ }^{13} \mathrm{C}$ NMR: $\delta$ $95.27,80.15,72.73,69.83,72.62,60.86\left(\mathrm{C}-1 / 1^{\prime}\right.$ to $\left.\mathrm{C}-6 / 6^{\prime}\right)$, $104.57,74.51,76.59,70.73,76.75$, and $61.73\left(\mathrm{C}-1^{\prime \prime} / 1^{\prime \prime \prime}\right.$ to C-6"' $\left./ 6^{\prime \prime \prime}\right)$.

Acid hydrolysis of $\mathbf{2}$. The deacylated tetrasaccharide (2) ( $1 \mathrm{mg}$ ) was dissolved in $\mathrm{H}_{2} \mathrm{O}(0.1 \mathrm{ml})$ and TFA $(0.1 \mathrm{ml})$ in a Teflon-capped vial and heated at $120^{\circ} \mathrm{C}$ for $1 \mathrm{~h}$, followed by lyophilisation. The residue proved identical with D-glucose.

\section{References}

1. Höltzel, A., Kempter, C., Metzger, J. W., Jung, G., Groth, I., Fritz, T. and Fiedler, H.-P. J. Antibiot. Submitted for publication.

2. Fiedler, H.-P. Nat. Prod. Lett. 2 (1993) 119.

3. Bérdy, J. Biotekhnologiya 7 (1995) 3.

4. Sanglier, J. J., Haag, H., Huck, T. A. and Fehr, T. Exp. Opin. Invest. Drugs 5 (1996) 207.

5. Nadkarni, S. R.. Patel. M. V., Chatterjee, S.. Vijayakumar, E. K. S., Desikan, K. R., Blumbach, J. and Ganguli, B. N. J. Antibiot. 47 (1994) 334.

6. Zwicker, N., Theobald, U., Zähner, H. and Fiedler, H.-P. J. Ind. Microbiol. Biotechnol. 19 (1997) 280.

Received March 6, 1998. 